\title{
Consumo e distinção social: abordagens convergentes sobre o caso da moda e vestuário em Veblen e Sahlins
}

\author{
Sebastião Neto Ribeiro Guedes ${ }^{1}$ \\ Rodrigo Constantino Jerônimo ${ }^{1}$ \\ Álvaro Martins Siqueira ${ }^{1}$ \\ Thiago Cordeiro da Silva ${ }^{1}$
}

\begin{abstract}
Resumo: O presente artigo busca comparar e examinar as similaridades entre as abordagens heterodoxas sobre o consumo de acordo com a Escola Econômica Institucional Original, a Sociologia Econômica e a Antropologia Econômica. Dessa forma, o texto dá atenção especial às análises de Thorstein Veblen e Marshall Sahlins para o caso do consumo de moda e vestimenta nos Estados Unidos. O artigo debate que a observação do caso de consumo de vestimenta, assim como suas ideias resultantes oferecem uma ligação entre Veblen na Economia e Sahlins na Antropologia, unindo ambos às ideias da Sociologia Econômica de distinção social em Bourdieu. O texto também debate que, apesar de escreverem em diferentes épocas, contextos e por meio de escolas de pensamento distintas, ambos os autores rejeitam os pressupostos neoclássicos de consumo baseados na maximização da utilidade. Em vez disso, apresentam esse assunto como uma questão de determinação cultural e de influências dos hábitos sociais imersos em propósitos não-maximizadores, puramente motivados pela busca de distinção social e demonstração de poder simbólico, questionando a racionalidade das decisões econômicas dos agentes.
\end{abstract}

Palavras-chave: Consumo. Institucionalismo Original. Sociologia Econômica. Vestimenta.

Comsumption and social distinction: convergent approaches on the fashion and dressig case in Veblen and Sahlins

\begin{abstract}
This paper aims to compare and examine the similarities between the heterodox approaches to consumption according to the Original School of Institutional Economics, Economic Sociology and Economic Anthropology. In order to do so, the text focuses on Thorstein Veblen and Marshall Sahlins' analysis to the case of consumption of fashion and apparel in the United States. The paper discusses the observations on the case of apparel consumption and their resultant ideas connect

1 Os autores são, respectivamente, professor livre-docente do departamento de Economia da Unesp/Araraquara; doutorando em Economia do PPGE/Unesp; doutorando do Programa de Pósgraduação em Economia da UFF; doutorando em Economia do PPGE/Unesp.
\end{abstract}


Veblen in Economics and Sahlins in Anthropology, also linking these approaches to the Economic Sociology ideas from Bourdieu's social distinction. The paper also discusses that, despite having written in different periods, contexts and through distinct schools of thought, both authors reject the neoclassical assumptions of utility maximization based consumption. Instead, they presented this subject as a matter of cultural determination and influences of social habits embedded in non-maximization purposes, purely motivated by the pursuit of social distinction and demonstration of symbolical power, and questioning the rationality of the agents' economic decisions.

Keywords: Consumption. Original Institutionalism. Economic Sociology. Apparel.

Classificação JEL: B150, B250

\section{Introdução}

O presente artigo tem como objetivo apresentar as semelhanças teóricas entre a Escola Econômica Institucional Original (OIE) e a abordagem de autores da sociologia e da antropologia econômica sobre o conceito de consumo. Em especial, este texto utilizará as reflexões feitas por Thorstein Veblen e Marshall Sahlins sobre o consumo no âmbito da moda e do vestuário, demonstrando o caráter social e simbólico da formação de preferências e as suas particularidades, em oposição à racionalidade plena do referencial teórico do mainstream econômico. Contrários à concepção do bomo economicus maximizador de utilidade, os autores aqui apresentados permitem, por meio de uma análise da formação social da economia, que seu leitor compreenda o consumo como uma esfera da economia dotada de interesses, motivações, hábitos e instintos, os quais estão deslocados de uma noção de racionalidade estrita.

Ao valer-se da concepção de Pierre Bourdieu (2007) - na qual os elementos culturais são utilizados como um meio de distinção entre as classes, de modo que estas buscam demonstrar o seu capital simbólico, com vistas a se diferenciar de seus pares -, esse artigo também demonstra as afinidades do pano de fundo teórico da sociologia com a temática aqui proposta. Outros autores já propuseram reflexões sobre o diálogo entre as teorias de Veblen e Bourdieu sobre as influências da cultura na realidade econômica (VALIATI; FONSECA, 2014; TRIGG, 2011). Desta forma, partirmos da metodologia utilizada em cada uma dessas reflexões em nossa proposta de relacionar o pensamento de Veblen ao pensamento de Sahlins, sem falhar na correta exegese dos textos da sociologia que serão utilizados como base teórica.

A relação proposta por este artigo entre a Escola Institucional Original e os ramos da sociologia e antropologia econômica é proposital, visto que os principais expoentes da primeira foram defensores da aproximação entre a economia e as 
ciências sociais, e advogaram em favor da interdisciplinaridade. Deste modo, o objetivo secundário deste trabalho é também buscar agendas conjuntas de pesquisa entre essas vertentes teóricas, munindo-as com ferramentas valiosas para análises no campo econômico, em especial na abordagem sobre o consumo.

O texto está organizado da seguinte forma: após a apresentação da proposta deste artigo em sua introdução, o segundo tópico examina rapidamente os pressupostos teóricos do mainstream econômico quanto ao tratamento do consumo, representado principalmente pela teoria do consumidor maximizador. $O$ terceiro tópico apresenta as principais abordagens do consumo no campo da sociologia. $\mathrm{O}$ quarto tópico discute a reação da abordagem institucional original frente à teoria do consumidor, apresentando o pensamento de Thorstein Veblen e seu conceito de Consumo Conspícuo como base para uma análise do consumo enquanto modo de distinção. O quinto tópico examina o ponto de vista de Sahlins para uma caracterização do consumo como demonstração de poder, evidenciando como a cultura e o simbolismo estão subjacentes à chamada racionalidade econômica. A última sessão traz as reflexões e considerações finais do artigo.

\section{Uma breve incursão na Teoria Neoclássica do Consumo}

O objetivo desta seção é resumir as principais características que a teoria do consumo apresenta na ótica neoclássica. Vale notar que não é nosso intuito demonstrar matematicamente as deduções e pressupostos incorporados pela teoria neoclássica (para uma incursão nesse tema, ver Mas-Colell et al. (1995); Varian $(2010,2014))$.

Os conceitos básicos e a filosofia por trás da teoria neoclássica do consumo estão definidos na teoria microeconômica. $\mathrm{O}$ consumidor é a figura central nessa teoria e, quase sempre, o primeiro passo é modelar seu comportamento (Varian, 2014).

De acordo com Kreps (1990), a microeconomia neoclássica trata do comportamento de atores econômicos individuais e do conjunto de suas ações em diferentes estruturas institucionais. Os atores individuais são tradicionalmente um consumidor ou uma firma. O comportamento do consumidor envolve alguma função de maximização de utilidade, enquanto que o comportamento das firmas envolve alguma função de maximização dos lucros. A estrutura institucional descreve quais opções os atores individuais possuem e quais resultados eles recebem a partir da ação dos demais atores. Essa relação ocorre pelo mecanismo de preços, em um mercado teoricamente neutro. Para modelar como os agentes se comportarão dentro de uma determinada estrutura, utiliza-se uma análise de equilíbrio.

$\mathrm{Na}$ abordagem tradicional, o comportamento dos atores sempre é modelado por meio de alguma função de maximização restrita. $\mathrm{O}$ ator escolhe a partir de algum 
conjunto específico de opções e seleciona aquela que maximizará uma determinada função-objetivo. $\mathrm{Na}$ teoria ortodoxa, os consumidores têm preferências, representadas por uma função-utilidade e as elegem de modo a maximizar as suas utilidades, sujeitos à uma restrição orçamentária. As firmas, por sua vez, maximizam seus lucros, com restrições impostas por seus conjuntos de possibilidades tecnológicas e de produção.

No que se refere à estrutura institucional, uma característica importante a se notar é que a tomada de decisão de qualquer indivíduo dependerá das oportunidades a ele apresentadas. Estas, por sua vez, geralmente dependem da ação coletiva dos demais indivíduos. Assim, o termo estrutura institucional é geralmente usado para se referir às características de um modelo que descrevem (a) a natureza geral das opções que um indivíduo possui; e (b) as opções disponíveis e os resultados possíveis para cada indivíduo, como uma função das ações dos demais indivíduos.

Nos modelos microeconômicos tradicionais, são os preços, em um mercado neutro, que constituem a estrutura institucional. Dados os preços dos bens, os consumidores podem escolher qualquer cesta de bens que conseguirem pagar. $\mathrm{O}$ mercado é neutro no sentido de que todos os consumidores enfrentam a mesma matriz de preços. Além disso, as escolhas disponíveis para um consumidor dependem das escolhas de consumo de todos os demais consumidores (e das escolhas de produção das firmas), dados os preços. Note que há certa circularidade, mas também ambiguidade nesse mecanismo de preços: ao mesmo tempo em que os preços restringem as escolhas dos consumidores, estas determinam os preços. Ademais, questões como de onde vêm os preços, como são determinados e como eles refletem nas ações dos consumidores permanecem pouco explicadas e convincentes.

Tendo modelado o comportamento dos indivíduos, a natureza das suas possíveis escolhas e o modo pelo qual suas ações afetam os demais, o passo seguinte é determinar o resultado disso tudo, ou seja, prever quais ações serão escolhidas e quais resultados serão obtidos. Para tanto, a teoria microeconômica faz uso de diversas formas de análises de equilíbrio. Vale dizer que, no geral, o equilíbrio na abordagem neoclássica é uma situação na qual cada indivíduo encontra-se tão bem quanto poderia estar, dadas as ações tomadas pelos demais atores e a estrutura institucional.

Note que uma característica importante da teoria do consumo para a abordagem neoclássica é o arcabouço utilitarista nela incorporado. A ideia de maximização de utilidade é a expressão maior do interesse utilitário presente nas teorias neoclássicas; sua lógica é a maximização das relações meios-fins. Ademais, há que se referir ao problema da auto-referência do comportamento racional substantivo, cuja inconsistência lógica foi exemplificada da seguinte forma por Knudsen (1993:147). 
Em um exemplo simples de dois agentes isto implica que o primeiro agente deve ser informado do conhecimento que tem o segundo agente, uma vez que o futuro parcialmente depende da sua ação. Mas parte do conhecimento desse segundo agente consistirá do que ele sabe sobre o conhecimento do primeiro agente, e assim ad infinitum. Este problema da auto-referência conduz a um problema de regresso infinito que de acordo com Oskar Morgenstern torna impossível aos agentes envolvidos justificar suas crenças como perfeitamente racionais.

São principalmente nesses aspectos da teoria que autores como Thorstein Veblen e Marshall Sahlins confrontarão a abordagem neoclássica do consumo.

\section{O estudo do consumo na Sociologia}

As raízes empíricas dos estudos sobre o consumo remetem ao desenvolvimento de métodos estatísticos. Concomitantemente, os primeiros orçamentos familiares eram coletados na Europa, em meados do século XIX, para determinar o mínimo de renda necessário para a subsistência. O foco principal era o consumo de alimentos e o desenvolvimento teórico ainda era bastante incipiente.

Embora a dualidade do valor (entre valor de troca e valor de uso) estivesse presente na economia clássica, foi somente com o aprofundamento analítico feito por Karl Marx (1976) entre o valor de uso e o valor de troca das mercadorias, que o estudo do consumo começou a alcançar maior rigor formal. Não convém aos limites deste artigo uma exposição detalhada do pensamento de Marx, porém alguns pontos devem ser esclarecidos, uma vez que foram determinantes para os desdobramentos posteriores, tanto na sociologia, quanto na antropologia do consumo ${ }^{2}$.

Marx sugeria que, em uma economia de mercado, as mercadorias não eram mais produzidas para o consumo próprio, mas para a troca no mercado. Assim, as relações de produção entre as pessoas ficavam cada vez mais obscurecidas, à medida que se transformavam em relações entre as próprias mercadorias. A esse fenômeno, Marx cunhou a definição de "fetichismo da mercadoria".

É importante esclarecer que o autor não considerava problemático o consumo na sociedade, mesmo existindo trabalhadores que não ganhavam o suficiente nem para reproduzir suas forças de trabalho. A esse problema, Marx atribuía culpa às relações de produção da sociedade. No geral, Marx considerava que o consumo era subordinado à produção, com a ressalva de que "o consumo cria a necessidade de uma nova produção, ou seja, o fundamento ideal, que move internamente a produção, e que é sua pressuposição" (Marx, 1982:8). Essa era uma visão bastante compartilhada naquela

2 Sahlins, por exemplo, contesta fortemente grande parte dos pressupostos de Marx. 
época; as pessoas eram consideradas, em primeiro lugar, produtores - bomo faber - e o conceito de consumo não tinha ainda sua conotação simbólica (Ilmonen et al., 2011).

De acordo com Ilmonen et al. (2011), pode-se separar o estudo sociológico do consumo em três estágios. O primeiro deles, que o autor chama de estágio "clássico" da sociologia, é quando o consumo passa a receber atenção como uma esfera distinta da atividade humana. Esse primeiro estágio acompanha a industrialização do século XIX, um momento marcado por uma inédita onda de mercadorias para consumo inseridas no mercado.

Nesse primeiro momento, a visão dos sociólogos não era unificada. Alguns, como Émile Durkheim (1995), consideravam o consumismo como a causa final de uma nova condição social de "anomia", um estado de falta de objetivos e perda de identidade provado pelas intensas mudanças na sociedade.

Outros, em contrapartida, deixavam de lado a problemática moral por trás do consumo e o consideravam como parte integrante do crescimento e do desenvolvimento do capitalismo. O consumo passava a ser visto como parte do modo de vida moderno, no qual os "bens de luxo" ganhavam grande importância e a moda passava a ser um aspecto muito relevante. Autores como Gabriel Tarde ${ }^{3}$ consideravam a moda uma forma de indicar o desejo ilimitado das pessoas imitarem os outros.

George Simmel, em seu trabalho seminal, "The Philosophy of Money" (1900), foi um dos primeiros a explorar o papel do dinheiro como mediador do consumo. $\mathrm{O}$ autor também chamava atenção para a proeminência do consumo como manifestação do estilo de vida metropolitano e para os mecanismos da moda no mundo moderno. $\mathrm{Na}$ visão de Simmel, a moda tinha grande relação com as classes sociais, no sentido de que os mais ricos descartavam determinada moda a partir do momento em que as classes sociais mais baixas começavam a utilizá-la.

Apesar de Simmel tratar desse aspecto, quem realmente criou essa teoria (trickle-down theory) foi Torstein Veblen, ao descrever as tendências das classes mais altas a se afastarem das demais classes sociais por meio do consumo conspícuo. No geral, isso envolvia a compra de mercadorias mais caras como forma de expressar o pertencimento a uma classe social mais elevada. À medida que o consumo dessas "mercadorias de status" ia se alastrando pelas demais camadas da sociedade, as classes altas se sentiam pressionadas a expandir cada vez mais o consumo, de modo a demonstrar seu status diferenciado.

$\mathrm{Na}$ periodização de Ilmonen et al. (2011), o segundo estágio da sociologia iniciou-se no período entre guerras e tomou mais fôlego após a Segunda Guerra Mundial. Foi nesse período que Marcel Mauss (1990) observou que a troca de favores/presentes não era tão altruísta como poderia parecer num primeiro momento. $\mathrm{Na}$ prática, segundo a teoria do autor, todo mundo que dá um presente ou presta um

3 Um dos principais críticos da sociologia de Durkheim. 
favor espera receber algo em troca, mesmo negando isso. As observações de Mauss tiveram grande alcance e implicações para a sociologia do consumo.

Nesse mesmo período, Walter Benjamin (1939), seguindo a linha dos trabalhos de Simmel, descrevia o modo de vida nas grandes metrópoles. A principal diferença entre os autores é que o primeiro via a moda como manifestação do tempo e não da classe.

Theodor W. Adorno e Max Horkheimer (1979), por sua vez, criticaram fortemente o crescimento do "fetichismo da mercadoria" na cultura popular. No entanto, suas críticas não se dirigiam ao consumo tão somente. Em última instância, o que os autores queriam mostrar era que, devido à subordinação dos valores de uso aos valores de troca, a sociedade capitalista tenderia a um fim em si mesma. Esse tema seria estudado posteriormente, tanto na sociologia alemã, quanto na americana ${ }^{4}$.

Note que, até esse momento, a maioria das análises sociológicas sobre o consumo envolviam um forte elemento moralizante. Foi somente a partir da década de 1970 que o consumo passou a ser abordado como uma atividade social significativa, que fornecia uma visão única nas várias facetas da sociedade. Para Ilmonen et al. (2011), esse momento marca o terceiro estágio da sociologia do consumo e é quando a disciplina começa a tomar forma ${ }^{5}$. É nesse estágio que autores como Pierre Bourdieu e Marshall Sahlins estão inseridos.

A proposta deste artigo se concentra nos esforços de outros autores para uma aproximação entre a EIO e o pensamento da Sociologia e Antropologia Econômica. Para o caso da Sociologia Econômica, enfatizamos brevemente o papel de Pierre Bourdieu e a sua teorização sobre a distinção social pela posse de capital social na obra "A distinção: crítica social do julgamento" (2007). Assim como esquematizado por VALIATI \& FONSECA, o pensamento de Bourdieu sobre o papel da legitimidade atribuída pela sociedade para a definição das práticas de consumo está diretamente associado ao objeto de estudo Vebleniano apresentado a frente. O objeto consumido está relacionado a um termo simbólico - a reputação - que por sua vez, é a base para o comportamento econômico do consumo conspícuo de Veblen.

A relação entre esses dois autores é fortemente defendida em Trigg (2001), pois este afirma que a teoria do consumo conspícuo, assim como apresentada por Veblen, teria sido deturpada e mal interpretada com o passar do tempo. Deste modo, Bourdieu poderia ser utilizado como uma resposta aos principais ataques desses erros de interpretação, pois ele "provê um desenvolvimento contemporâneo da teoria do

4 É importante notar que as raízes desses estudos já estavam em Adam Smith (1904), em sua crítica ao "consumo desnecessário".

5 Na verdade, alguns autores já esboçavam alguns estudos nesse sentido, como David Riesman (1969), que já na década de 1950 argumentava que estaria sendo desenvolvido um novo tipo moderno de "personalidade orientada para fora" (outer-directed personality), na qual o consumo se tornava um aspecto central da vida cotidiana. 
consumo conspícuo que se baseia em alguns dos aspectos mais sutis da estrutura de Veblen" (TRIGG, 2001, p. 104). As principais semelhanças entre as duas teorias e os pontos de encontro para defesa da teoria Vebleniana estariam (i) na cultura das classes altas impedindo a mobilidade social e no conceito de capital cultural, (ii) no conceito de habitus e na defesa do consumo conspícuo como uma ação inconsciente padronizada e (iii) "na aceitação de que a estrutura social é determinada pelo e determina o comportamento dos indivíduos” (ibid. p. 113).

\section{Veblen e a instituição do consumo: moda como distinção}

Considerado como um dos fundadores do Institucionalismo norte-americano no início do século XX, Thorstein Veblen (1857-1929) teve papel fundamental na formação e na teorização dessa escola de pensamento, principalmente por seu caráter de negação do comportamento racional dos agentes, ao se contrapor aos pressupostos apresentados pela ortodoxia econômica. Em seu artigo Why Is Economics not an Evolutionary Science, de 1898, Veblen apresenta as bases para a necessidade da busca por uma abordagem evolucionária nas ciências econômicas, evidenciando o papel da ação coletiva e dos hábitos mentais nas mudanças sociais. De fato, autores como Hodgson (1988) consideram o pensamento vebleniano como sendo pioneiro na criação da economia institucional, tendo como principal elemento a estrutura evolucionária de Darwin e seu caráter não estático e não teleológico, deixando clara a sua rejeição aos elementos de equilíbrio mecânico da teoria neoclássica e do historicismo marxista.

A heterodoxia econômica representada pelo institucionalismo norteamericano teve na figura de seus idealizadores (Veblen, John Commons e Wesley Mitchel) a importante caracterização das instituições como ponto de partida para o estudo das ciências econômicas. Independentemente da sua forma, sejam contratos, leis ou padrões de pensamentos, as instituições são representações do modo como a ação coletiva se organiza e opera no dia a dia de cada sociedade. Nas instituições, o comportamento dos agentes é definido, sendo este, por sua vez, a própria representação do comportamento socialmente aceito pelos seus pares e tendo como principais influências para sua determinação os interesses coletivos e as mudanças ambientais a sua volta. Deste modo, a trajetória das mudanças institucionais está longe de ser caracterizada pelo equilíbrio mainstream, pois a ação coletiva não segue comportamentos que maximizam seus resultados. Ao contrário, a vida econômica é um acúmulo de mudanças que formam a sociedade em direção a um fim não pré-determinado.

As instituições são, para Veblen, o acúmulo das experiências que estão nos hábitos de pensamento dos membros de determinada sociedade. Hodgson (2004) 
apresenta o conceito de instituições de Veblen como sendo os "armazéns de conhecimento social”, uma vez que a cognição humana e as características de comportamentos do passado influenciam o comportamento dos indivíduos no presente. As experiências do passado estão presentes nos hábitos da sociedade contemporânea e, de fato, os indivíduos já nascem em estruturas definidas, que farão parte da sua formação cognitiva. Tal estoque de conhecimento e de comportamentos não anularia a característica de cada indivíduo como agente ativo no processo de formação institucional, uma vez que Veblen afirma a interdependência entre indivíduos e estrutura social sem que uma se sobressaia a outra.

Indivíduos formam e são formados pelas estruturas e instituições do seu ambiente. Sendo assim, a mudança institucional ocorrerá da sua capacidade de aprender e inovar a partir do que adquiriu com os outros; portanto, "o indivíduo e os aspectos sociais do conhecimento estão conectados porque o ambiente social e seu estoque comum de experiência provêm os meios e estímulos para o aprendizado dos indivíduos" (ibid., p. 183).

De que modo podem surgir as mudanças no padrão de pensamento em uma determinada sociedade e como tais mudanças cognitivas podem determinar o comportamento dos agentes econômicos? A resposta vebleniana para tal indagação atribui aos instintos de artesanato e de criatividade a possibilidade de inovação frente à sequência de hábitos acumulados até então. A concepção de instituições vigentes é sintetizada por Almeida (1983) como "o conjunto de hábitos, costumes e modos de pensar cristalizados em práticas aceitas e incorporadas pela comunidade”, ou seja, as instituições permanecem por representarem o que é socialmente aceito e assim legitimado. A capacidade de rompimento com essas instituições ocorre de modo gradual, à medida que as inovações no comportamento dos indivíduos são incorporadas no padrão de pensamento do grupo.

O vestuário é tomado por Veblen como uma das principais formas recebidas pela sociedade pecuniária para a demonstração de distinção entre os indivíduos. Tal afirmação resulta da teorização feita pelo autor em sua obra "Teoria da Classe Ociosa" (1983), na qual o conceito-chave de consumo conspícuo é apresentado como sendo resultante das modificações de uma sociedade primitiva selvagem para uma sociedade bárbara, na qual a comunidade é dividida em funções indignas e funções de honra, e na qual questões como proeza e façanha eram tomadas como os principais elementos de distinção entre os homens. A motivação pela busca incessante de distinção está na chamada "emulação pecuniária", ou seja, a competição em busca da superação entre os indivíduos na busca de maior reputação.

O vestuário passa a possuir atributos econômicos a partir do momento em que este pode ser utilizado como um sinal da riqueza de alguém, o que na visão de Veblen, 
é o seu papel principal. Desta forma, o consumo conspícuo está relacionado ao gasto da seguinte maneira

\begin{abstract}
Não é que aquele que veste ou que os compradores desses bens de desperdício desejam gastar. $\mathrm{O}$ seu desejo é manifestar a sua habilidade de pagar. $\mathrm{O}$ que os indivíduos buscam não é o gasto de facto, mas a aparência do gasto. (...). Este fato de que o objeto buscado não é o desperdício, mas a demonstração dele, desenvolve-se em uma pseudo-economia no uso desse material (Veblen, 1894, p.201).
\end{abstract}

A emulação pecuniária está associada, por sua vez, ao que Veblen chama de "comparação odiosa" entre os indivíduos, indicando que é comum entre os homens a comparação da condição pecuniária em termos relativos. Independentemente da sua condição passada com relação ao presente, as pessoas sempre olhariam para os seus pares buscando a comparação de status e de crescimento. A acumulação pelo consumo conspícuo é resultado do desejo pela distinção dos demais e está associada ao consumo habitual daquilo que é valorizado unanimemente pela sociedade.

As evoluções no padrão de pensamento, a saber, nas instituições sociais, demonstram um papel fundamental nas mudanças de comportamento dos indivíduos quanto ao modo em que estes embasam a sua busca pela distinção. Uma vez que a sociedade caminha gradualmente para a vida industrial, a proeza da batalha, das caças e de qualquer outra atividade costumeiramente aceita na sociedade como digna (como esportes e religião) abre espaço para novas formas de distinção não ligadas a qualquer façanha humana.

Para Veblen, o modo de distinção na sociedade industrial passa a ser o acúmulo de riquezas, especificamente o excedente da produção, demonstrando o sucesso dos seus detentores. A emulação pecuniária faz com que "o instinto de artesanato ou vontade de realização tenda a tomar a forma de um esforço para sobrepujar os outros em realizações pecuniárias" (VEBLEN, 1894). A fase industrial traz consigo uma classe ociosa, ausente de atividades laboriosas, cuja participação em alguma dessas seria considerada desonrosa, que tem como característica sua distinção pelo acúmulo de riquezas e vai além daquela considerada de subsistência. Deste modo, demonstra-se que a motivação para o acúmulo de riquezas está distante de uma racionalidade otimizadora, e sim, próxima de aspectos "irracionais" da busca pela distinção, aceitação, honra e poder pecuniário na sociedade.

O modo como as pessoas se vestem e a moda dominante em determinado período são tomados por Veblen como exemplos claros da cultura pecuniária, em que os princípios do consumo conspícuo e do ócio conspícuo são demonstrados com maior evidência no comportamento da sociedade. Os trajes utilizados pelos indivíduos têm a capacidade de demonstrar o poder pecuniário do seu detentor, pois 
estão à vista de todos e representam as regalias que tal indivíduo tem frente ao trabalho. Como no caso a seguir:

Grande parte do atrativo de que se reveste o calçado de couro legítimo, a roupa branca imaculada, a luzidia cartola cilíndrica e a bengala, que tanto fazem realçar a dignidade inata do cavalheiro, provêm de os mesmos sugerirem incisivamente que aqueles que os traz não pode, assim vestido, dar ajuda a qualquer ofício que seja direta e imediatamente de utilidade humana (VEBLEN, 1983, p.78-79).

A exposição de que o indivíduo pode abster-se do trabalho é observada na capacidade do seu vestiário de impedi-lo de desempenhar qualquer atividade que exija o esforço físico, o que seria considerado de pouca honra. É notório que, para Veblen, o consumo de roupas está diretamente associado à necessidade de os indivíduos alcançarem a respeitabilidade e a honra, por pertencerem a uma classe capaz de manter um consumo conspícuo, sem a necessidade de trabalhar para tanto. O consumo está, portanto, descolado de concepções como razão ou utilidade, sendo marcado por competição e imitação, mesmo que isso implique em dificuldades para aquele que consome. Quanto mais uma vestimenta se mostra desconfortável, de difícil manuseio e indique o ócio de quem o utiliza, mais valorizada ela será e representará força pecuniária na sociedade (VEBLEN, 1983).

A obra de Veblen apresenta o consumo conspícuo como a característica dominante do capitalismo moderno, não só pela distinção resultante da demonstração de poder pecuniário, como também pela capacidade que a classe ociosa tem de usá-la para definir os gostos, a moda e o status. Isto é, ao utilizar-se do vestuário, as classes mais baixas tendem a imitar os hábitos mentais e os gostos sociais das classes mais altas, ainda que tal imitação traga restrições quando comparadas às suas roupas do dia a dia. Esse parece ser o caso da utilização de espartilhos pelas mulheres de classes inferiores:

(...) O espartilho é usado tão somente em certas camadas sociais razoavelmente definidas. As mulheres das classes mais pobres, especialmente da população rural, habitualmente não o usam, exceto como luxo domingueiro. Nessas classes, as mulheres têm de trabalhar arduamente e pouco lhes adianta, sob pretexto do ócio, crucificar a própria carne na vida cotidiana. O uso domingueiro do colete é devido à imitação de uma regra de respeitabilidade da classe mais alta (...) Em todos os países que herdaram o colete, esse continua sendo usado, onde quer e enquanto servir ao propósito de provar o ócio honorífico por via da inaptidão física de quem o usa (VEBLEN, 1983, p. 84).

A vestimenta das mulheres tem papel fundamental na teoria econômica da moda proposta por Veblen, principalmente como modo de demonstração do poder 
pecuniário masculino. A esse tema coube atenção especial do autor em seu artigo The Economic Theory of Women's Dress (1894). Parte dessa concepção está no tratamento da esposa como propriedade do seu marido e representação clara do seu poder pecuniário. Assim como apontado por Hellmann (2009), em uma sociedade pósRevolução Francesa, que exigia do homem uma vestimenta neutra e sóbria, "as mulheres acabam se convertendo em representantes, por excelência, da riqueza do marido" (ibid., p.49).

Veblen resume a teoria da vestimenta feminina em três princípios fundamentais. Primeiramente ao preço elevado, de modo que o comprador demonstre o poder de adquirir um bem caro, sem que haja retornos de custo-benefício em sua aquisição, ou seja, o consumo conspícuo. Em segundo lugar está o princípio da novidade, o mesmo do qual se origina a tendência da moda, pregando que, além de caro, o vestuário feminino deve ser novo e usado poucas vezes, até mesmo apenas uma vez, como é o caso dos vestidos de festa. E, por fim, está o princípio da ineptidão, ou seja, a demonstração clara de que o indivíduo está impossibilitado de fazer qualquer esforço útil e laborioso enquanto faz uso de sua roupa (Veblen, 1894, p. 204).

Os princípios apresentados são facilmente observados nas vestimentas femininas, pois, segundo Veblen, a herança de uma sociedade patriarcal ainda marca os padrões da sociedade que ele observa. De modo que "o lugar da mulher (de acordo com o nosso sistema social) tornou-se um meio de gasto conspícuo improdutivo", a mulher "é tratada como uma posse pecuniária, tornando-se de modo peculiar, um expoente da força pecuniária do seu grupo social” (Veblen, 1984, p. 200). Conforme comentou um estudioso da obra de Veblen (DIGGINS, 1999, p. 166):

\begin{abstract}
A posição da mulher é o produto das relações de poder que se originam em primitivos atos de coerção, relações que se tornaram reificadas como costumes "naturais" e assim ganharam o status científico, bem como de ideologia moral. Ao traçar as origens de brutalidade da hegemonia masculina, Veblen reorientou a consciência social nos mostrando porque atos de poder nunca podem ser dignificados com o uso da autoridade.
\end{abstract}

Os argumentos apresentados nessa seção demonstram as influências da cultura pecuniária no modo como os indivíduos são levados a consumir. A racionalidade aqui presente, se assim podemos chamá-la, não busca a maximização ou a utilidade, como bem se esperaria em se tratando de bens que potencialmente poderiam trazer conforto e bem-estar ao seu possuidor. Antes, sua motivação é a demonstração do poder pecuniário pelo acúmulo de bens, prova clara da sua possibilidade de mostrar-se próspero sem atividade laboriosa e alcançar prestígio da sociedade. 


\section{Marshall Sahlins e a antropologia do consumo: notas sobre o sistema de vestuário americano}

Sahlins refletiu sobre a Antropologia em um momento em que a disciplina iniciava a sucumbir aos encantos da abordagem da "racionalidade" (Teófilo da Silva, 2002). Sua contribuição teórica pode ser entendida, em certo sentido, como uma reação àquele avanço. Ela se manifestou inicialmente como uma crítica à definição da atividade econômica como a aplicação racional dos recursos escassos aos fins alternativos. Contida nessa definição, estava a ideia de que os desejos e vontades humanas seriam infinitos, devendo contudo, se ajustar aos recursos disponíveis para alcançá-los. A racionalidade individual cuidaria então de ajustar meios (escassos) a fins (infinitos). Mas essa representação do "problema econômico" era adequada?

Para Sahlins, claramente não. Para argumentar criticamente, ele estudou a economia pré-histórica dos grupos coletores e caçadores do paleolítico. Ele observou que as evidências reunidas por etnógrafos e viajantes revelaram sociedades pobres, mas distantes das representações negativas que abordagens etnocêntricas lhes imputavam. Eram sociedades organizadas por princípios distintos daqueles supostos no homem econômico. Seus desejos e vontades eram limitados e finitos por deliberação consciente, "intenção cultural", o que tornava os meios disponíveis adequados para provê-los de relativo bem-estar material. Disso resultava que os homens do paleolítico eram livres de preocupações materiais, não possuíam sentimento de posse nem de propriedade, trabalhavam menos do que os homens da atualidade, tinham tempo livre e produziam excedente econômico. Contra a tendência à universalização do homem econômico, afirma Sahlins,

\footnotetext{
(...) eles [os grupos humanos do paleolítico] nos mostram que o "problema econômico" pode ser facilmente solucionado com técnicas paleolíticas. Mas, só quando a cultura atingiu o ápice de seu desenvolvimento material, erigiu um santuário ao inatingível: as necessidades infinitas (Sahlins,1978:43).
}

Sahlins é não apenas um crítico do utilitarismo presente na economia ortodoxa, mas também um crítico do materialismo histórico presente na obra de Marx. Para ele, ao tratar a produção como um processo "natural-pragmático" de satisfação de necessidades, tudo ocorreria na antropologia marxista como ocorre na economia ortodoxa, ou seja, como se o analista fosse logrado pelo mesmo fetichismo da mercadoria que enfeitiça os participantes no processo.

Nas palavras de Sahlins (2003, p. 108),

Concebendo-se a criação e o movimento de bens somente a partir de suas quantidades pecuniárias (valor de troca), ignora-se o código cultural de propriedades concretas que 
governa a "utilidade" e assim continua incapaz de dar conta do que é de fato produzido. A explicação se satisfaz em recriar a autoilusão da sociedade para a qual se dirige, onde o sistema lógico dos objetos e relações sociais segue em um plano inconsciente, manifestado somente através de decisões de mercado baseadas no preço, deixando a impressão de que a produção não passa de um precipitado de uma racionalidade esclarecida. A estrutura da economia aparece como a consequência objetivizada do comportamento prático, em vez de uma organização social de coisas, pelos meios institucionais do mercado, mas de acordo com um projeto cultural de pessoas e bens.

No entanto, o utilitarismo é o modo pelo qual a sociedade se experimenta, ou seja, a maneira como vivem os agentes em uma economia. Sob quaisquer aspectos, o processo parece ser de maximização material, de alocação ótima de meios escassos para obtenção da maior satisfação possível. Para o consumidor, é uma busca "racional" de felicidade, ou seja, é como se o retorno - em utilidade - da despesa monetária por determinado produto fosse superior a qualquer alternativa possível.

Nesse sentido, quando o comportamento do consumidor ao escolher determinado bem é analisado na sociedade moderna, afirma o autor:

O carro último tipo - ou o refrigerador, o estilo de roupa, ou a marca de dentifrício - é, por causa de uma nova característica ou outra mais conveniente, melhor adaptado às necessidades da vida moderna, mais confortável, tem mais saúde, é mais sexy, mais durável, ou mais atraente que qualquer produto competidor. (SAHLINS, 2003, pp. 108-9).

Mesmo parecendo ser assim que se mostra a sociedade, o esquema "racional" e "objetivo" nunca é o único possível. A produção, segundo Sahlins, é algo maior e diferente de uma prática lógica de eficiência material: é uma intenção cultural. É nesse aspecto que o autor discorda de Marx, já que este reservou a qualidade simbólica ao objeto em sua forma-mercadoria (fetichismo). Segundo Sahlins, admitindo que os valores de uso claramente servem às necessidades humanas por suas propriedades evidentes, Marx teria negligenciado as relações significativas entre homens e objetos, que são essenciais para compreender a produção em qualquer forma histórica. Em outras palavras, Marx não teria dado uma explicação cultural da produção, nem entendido a natureza do consumo como um sistema de comunicações, por meio do qual acontecem as trocas materiais e simbólicas.

Sahlins tenta explicar essa relação. Nas palavras do autor:

De maneira a situar uma resposta, a dar uma explicação cultural da produção, é crucial que se note que o significado social de um objeto, o que o faz útil a uma certa categoria de pessoas, é menos visível por suas propriedades físicas que pelo valor que pode ter na troca. 
O valor de uso não é menos simbólico ou menos arbitrário que o valor-mercadoria. Porque a "utilidade" não é uma qualidade do objeto, mas uma significação das qualidades objetivas. A razão pela qual os americanos determinam que a carne de cachorro não é comestível e a de boi o é, não é mais perceptível aos sentidos do que o preço da carne. Da mesma forma, o que determina que as calças são de uso masculino e as saias de uso feminino não tem necessariamente conexão com as características físicas ou com as relações que advêm dessas características. É por sua correlação em um sistema simbólico que as calças são produzidas para os homens e as saias para as mulheres, e não pela natureza do objeto em si nem por sua capacidade de satisfazer uma necessidade material - assim como é pelos valores culturais de homens e mulheres que os primeiros normalmente se incumbem dessa produção e as mulheres não. Nenhum objeto, nenhuma coisa é ou tem movimento na sociedade humana, exceto pela significação que os homens lhe atribuem. A produção é um momento funcional de uma estrutura social. (SAHLINS, 2003, p. 110).

Com o objetivo geral de contribuir para a explicação cultural da produção, ou seja, de que a produção é a realização de um esquema simbólico, Sahlins explora o código de propriedades do vestuário americano e de suas combinações significativas. Para o autor, a produção de vestuários é tanto uma caracterização de tempo e espaço quanto de status:

O que é produzido é, portanto, em primeiro lugar, tipos de tempo e de espaço que classificam situações ou atividades; e em segundo lugar, tipos de status aos quais todas as pessoas pertencem. Essas poderiam ser chamadas de “coordenadas nocionais" do vestuário, na medida em que demarcam noções básicas de tempo, lugar e pessoa como constituídos na ordem cultural. Daí ser esse esquema classificatório, o que é reproduzido no vestuário. No entanto, não é só isso. Não são simplesmente os limites, as divisões e subdivisões entre grupos etários ou classes sociais, por exemplo: por um simbolismo específico das diferenças no vestuário, o que é produzido são as diferenças significativas entre essas categorias. Ao manufaturar peças de vestuário de cortes, modelos ou cores diferentes para mulheres e para homens, reproduzimos a distinção entre feminilidade e masculinidade tal como é conhecida nessa sociedade. Isso é o que ocorre no processo pragmático-material da produção. (SAHLINS, 2003, p. 116).

Assim, o que ocorre é uma diferenciação do espaço cultural através das vestimentas, assim como a que ocorre entre campo e cidade. Uma pessoa que vai às compras, por exemplo, pode facilmente tornar elegante uma simples roupa doméstica ao adicionar alguns elementos de destaque, como por exemplo joias, relógios, colares e brincos. Da mesma forma, também se substancializa nas roupas as demarcações culturais de tempo - diário, semanal, sazonal - como, por exemplo, roupas para o dia 
e para a noite, para a semana e para os finais de semana, para o verão e para o inverno e assim por diante.

Segundo o autor, a produção capitalista deveria ser vista como um processo cultural. É claro que “essa produção é organizada de modo a explorar todas as possíveis diferenciações sociais através de uma motivada diferenciação de bens”. No entanto, “o capitalismo não é pura racionalidade. É uma forma definida de ordem cultural; ou uma ordem cultural agindo de forma particular” (SAHLINS, 2003, p. 118).

Em suma, ao analisar o sistema de vestuário americano, percebe-se que não se trata apenas de uma reprodução de objetos simplesmente úteis, mas significativos. A utilidade consiste em uma significação, em uma crença na existência de pertencimento a um determinado grupo de pessoas (totemismo) - uma manifestação simbólica de existência e de pertencimento. Nas palavras de Sahlins (2003, p. 128), "uma materialização suntuária das principais coordenadas de pessoa e ocasião torna-se um vasto esquema de comunicação - de maneira a servir como uma linguagem de vida do dia a dia entre aqueles que podem não ter tido relação de conhecimento anterior”. A esfera econômica é, portanto, determinada por uma esfera simbólica, de racionalidade criada pela sociedade em conjunto.

É nesse sistema de aparências que o sistema de vestuário manifesta uma "utilidade cultural e social", como constata Sahlins (2003, p. 128):

\begin{abstract}
"Mera aparência" deve ser uma das mais importantes formas de manifestação simbólica na civilização ocidental. Porque é através de aparências que a civilização transforma a contradição básica de sua construção em um milagre de existência: uma coesa sociedade de estranhos. Nesse caso, sua coesão depende de uma coerência de tipo específico: da possibilidade da apreensão dos outros, de suas condições sociais, e desse modo de suas relações com alguém "à primeira vista”. Essa dependência da visão ajuda a explicar, por um lado, por que as dimensões simbólicas, apesar disso, não são óbvias.
\end{abstract}

Essa dependência da "aparência" na análise do sistema de vestuário americano sugere a existência de uma lógica diferente da "racionalidade convencional" na vida econômica, social e também nas escolhas de consumo; enquanto a racionalidade esquecida de sua própria base cultural - continua considerando-se constitutiva das alternativas de escolhas e das opções de "indivíduos racionais". Além dessas, outras observações aproximam Sahlins do campo heterodoxo de reflexões econômicas. Em especial, sua afirmação sobre a natureza histórico-cultural do comportamento humano, que o imunizou (assim como a outros pensadores de extração crítica) de certas narrativas da antropologia moderna e que procura universalizar o comportamento racional-utilitarista do bomo-economicus a todas as formas de sociedades que antecederam o capitalismo. 


\section{Considerações finais}

O presente artigo teve como principal objetivo apresentar a aproximação teórica entre as abordagens de Veblen e Marshall Sahlins sobre o caráter institucional e cultural do consumo de vestimentas, demonstrando como ambos negaram o pressuposto neoclássico de racionalidade. Valendo-se do pensamento de Pierre Bourdieu sobre o comportamento da busca pela distinção social dada a posse do poder simbólico, o texto demonstrou como o consumo está diretamente relacionado às características culturais e aos padrões de comportamento da sociedade. A partir do estudo desses autores, pode-se encontrar bases para negar a racionalidade plena e maximizadora dos agentes econômicos em sua tomada de decisões quanto ao que consumir, dando ênfase a motivações, propósitos e interesses que não implicam em melhores escolhas de alocação de recursos.

O texto buscou desenvolver, a partir da ideia mainstream de racionalidade e de maximização, a resposta heterodoxa dada pelos pensadores da economia e sociologia para a questão do consumo. Em seguida, apresentou-se a teoria econômica de Veblen, enfatizando o caso das vestimentas como um objeto capaz de exemplificar as características da sociedade pecuniária, que busca a distinção social pelo consumo conspícuo, sendo uma forma de superar o sucesso dos outros agentes e de ganhar honra e prestígio dos seus pares. Em Veblen, o consumo é também um espaço competitivo, uma extensão da "emulação" dos mercados, mas não para obter o máximo prazer, e sim a distinção social e respeitabilidade dos demais atores sociais.

Sahlins flagrou o componente contraditório presente na ideia do homem econômico e seu problema econômico: ao afirmar - contra as evidências antropológicas - a existência de desejos infinitos, a sociedade burguesa transforma toda aquisição de bens em uma privação, "pois toda compra de alguma coisa é a falta de alguma coisa, em geral marginalmente menos desejável e em alguns detalhes mais desejável". A breve exposição feita ao final do artigo sobre a abordagem de Marshall Sahlins em relação às vestimentas nos Estados Unidos demonstra o papel da cultura sobre o comportamento de consumo dos agentes de determinada sociedade. Sahlins demonstra que, subjacente à racionalidade econômica, estão diversos símbolos culturais que influenciam a decisão econômica, pois a característica simbólica representa a narrativa de vida de um agente e seu consumo demonstra poder.

Embora a relação entre as diferentes escolas do pensamento aqui apresentadas tenha sido breve e voltada somente a um ponto comum entre elas - o consumo e o caso das vestimentas -, o campo de exploração entre as suas similaridades é vasto. Deste modo, o presente artigo buscou contribuir com outros trabalhos que também almejem apresentar uma aproximação da heterodoxia econômica com a sociologia e a antropologia, enriquecendo o debate comum desses campos de estudo. 


\section{Referências}

ALMEIDA, M. H. T. Apresentação. In: VEBLEN, T. A Teoria da Classe Ociosa: Um estudo econômico das instituições. Trad. Olívia Rähenbühl. São Paulo: Abril Cultural, 1983. pp. VII - XVII.

BOURDIEU, P. A distinção: crítica social do julgamento. Porto Alegre: Zouk, 2007.

DIGGINS, J.P. Thorsten Veblen theorist of the leisure class. Princeton: Princeton University Press, 1999.

HellmanN, A.G. A Moda no Século XXI: Para Além da Distinção Social? 2009. 121 f. Dissertação (Mestrado em Sociologia) - Instituto de Filosofia e Ciências Humanas, Universidade Federal do Rio Grande do Sul, Porto Alegre-RS. 2009.

HODGSON, G.M. The Evolution of Institutional Economics: agency, structure and Darwinism in American Institutionalism. Londres: Routledge, 2004. DOI: https://doi.org/10.4324/9780203300350

ILMONEN, K. et al. A Social and Economic Theory of Consumption. Palgrave Macmillan, London, 2011. DOI: https://doi.org/10.1057/9780230295339

KNUDSEN,C. Equilibrium, perfect rationality and the problem of self-reference in economics. In: Maki; Gustafsson; Knudsen. Rationality, institutions and economic methodology. London/New York: Routledge, 1993, p. 133-170. DOI: https://oi.org/ 10.4324/9780203392805_chapter_6

KREPS, D. M. A course in Microeconomic Theory. Princeton University Press, Princeton, 1990.

MARX, K. Para a crítica da Economia Política. São Paulo: ed.Abril, 1982.

MAS-COLELLl, A.; Whinston, M. D.; Green, J. R. Microeconomic Theory. Oxford University Press, New York, 1995.

PASSOS,L.P.P.A; CARNEIRO,T.C.J;SANTIANNA. O sujeito do consumo: algumas reflexões à luz de Giddens, Bourdieu e Sahlins. Intratextos, 3(1), p.111-123, 2011. DOI: https://doi.org/10.12957/intratextos.2011.2403 
SAHLINS, M. Cultura e Razão Prática. Rio de Janeiro: Zahar, 2003.

SAHLINS,M. A primeira sociedade da afluência. IN: Carvalho,E.A - Antropologia econômica. São Paulo:Livraria editora Ciências Humanas.1978, p-7-43.

TEÓFILO DA SILVA, C - Sobre a interpretação antropológica: Sahlins, Obeyekere e a racionalidade havaiana. Revista de Antropologia, v.45,n.2, p.403-415, 2002. DOI: https://doi.org/10.1590/S0034-77012002000200004

TRIGG, Andrew B. Veblen, Bourdieu, and conspicuous consumption. Journal of Economic Issues, London, v.35, n.1, p. 99-115, 2001. DOI: https://doi.org/10.1080/00213624.2001.11506342

VEBLEN, T. The Economic Theory of Woman's Dress. The Popular Science Monthly, New York, v.46, n.1, p. 198-205, 1894.

VEBLEN, T. A Teoria da Classe Ociosa: Um estudo econômico das instituições. Trad. Olívia Rähenbühl. São Paulo: Abril Cultural, 1983.

VALIATI, L; FONSECA, P.C. Institutions and Culture: Thorstein Veblen's and Pierre Bourdieu's economic thought in dialogue. Iberian Journal of the History of Economic Thought, Madrid, vol.1, n.1, p.1-17, 2014. DOI: https://doi.org/10.5209/rev_IJHE.2014.v1.n1.46642

VARIAN, H. R. Intermediate Microeconomics: A Modern Approach ( $8^{\text {th }}$ ed.). University of California at Berkeley, W. W. Norton \& Company, New York, 2010.

VARIAN, H. R. Intermediate Microeconomics with Calculus ( $1^{\text {st }}$ ed.). University of California at Berkeley, W. W. Norton \& Company, New York, 2014.

Recebido em 04.05.18 Aprovado em 07.11.18 